\title{
Examination of Affiliate Stigma, Hopelessness and Life Satisfaction in Parents of Children with Intellectual Disabilty
}

\author{
Necla Kasımoglu ${ }^{1^{*}}$ (D), Duygu Arıkan² (D)
}

\begin{abstract} members, especially parents. children with intellectual disability. with Life Scale. satisfaction was found to decrease. provide trainings and raise awareness against individuals with disabilities and their families.

\section{Keywords}

Affiliate Stigma; Child; Hopelessness; Intellectual Disability; Life Satisfaction; Nurse

${ }^{1}$ Department of Child Health Nursing, Faculty of Health Sciences, Erzincan Binali Yildirim University, Turkey

${ }^{2}$ Department of Child Health Nursing, Faculty of Nursing, Atatürk University, Erzurum, Turkey

*Corresponding author: necla_24celik@hotmail.com
\end{abstract}

Introduction. While expecting a healthy child, having a child with a disability can be quite traumatic for all family

The objective of the research was to evaluate affiliate stigma, hopelessness, and life satisfaction in parents of

Materials and Methods. The descriptive research included 203 parents of children with intellectual disabilities, who met the research inclusion criteria and agreed to participate in the study. The data were collected using the Personal Information Form, the Affiliate Stigma Scale, the Beck Hopelessness Scale, and the Satisfaction

Results. The mean age of parents included in the study was $40.74 \pm 7.22$ years, with $67.5 \%$ of caregiving mothers. The levels of affiliate stigma and hopelessness among parents were low, and they were satisfied with their lives. In case of increasing parental affiliate stigma, their hopelessness was found to increase, while life

Conclusions. In order to increase public acceptance of people with disabilities by society, it is recommended to

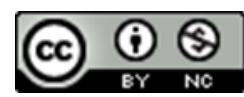

Copyright @Necla Kasımoglu, Duygu Arıkan, 2021

\section{Problem statement and analysis of the latest research}

Each couple wants to experience the family phenomenon, strengthen marriage and family ties, ensure the continuity of their generations, and have children in order to secure their future [1]. The fact that parents with normal development and expectation of a healthy baby learn that the development of their children to be born is abnormal, creates a very traumatic effect on parents, regardless of the degree of disability [2].

Intellectual disability refers to a particular state of functionality that begins before the age of 18 and is characterized by significant limitations in both conceptual, social, and practical adaptability skills, and intellectual and adaptive behavior [3].

The birth of a baby brings innovations, changes and dif- ficulties in family routines and relationships. The birth of a child with any disabilities may cause parents to face some difficulties in maintaining their daily lives and adapting to social life [4].

Studies conducted with parents of children with intellectual disabilities indicated that families do not receive social acceptance and support by society, disability is seen as a contagious disease by society, and they have difficulties in caring for their children due to negative perceptions of their children such as stigma [5,6]. As the treatment and rehabilitation of their children requires more manpower, cost and time than in case of caring for a healthy child, it has been observed that the physical, emotional, economic, social burden and time requirement of such families increased [7, 8]. Compared to parents of normally developing children, parents of children with intellectual disabilities have been determined to have 
higher levels of depression, anxiety, and stress, and lower capacity to accept and cope with distress [2].

Since the behaviors of children with intellectual disabilities are considered inappropriate and dangerous by society, both children and their families may be subjected to negative attitudes and discrimination by other individuals in society [9].

Stigmatization can be defined as attributing features that damage people's reputation in society due to their characteristics placing them in a low position. Affiliate stigma is defined as the perception of public stigmatizing views that create an acceptance in the individual's inner world affecting the dimension of emotions, thoughts, beliefs and fears [10].

Hopelessness is a state of emotion characterized by the absence, or inadequacy of hope and is a concept that defines that the individual usually has a pessimistic expectation or has no expectations for the future. Despair can negatively affect a person's ability to perceive themselves, their environment and other people around them, often causing a low mood [11].

Life satisfaction reflects an individual's overall feeling about their life and is considered a measure of emotional happiness. Life satisfaction, often defined as happiness, is one of the most important factors affecting people's mental health and social relationships [12].

Disabled individuals and their relatives exposed to stigmatization may experience varying levels of emotional injury, hopelessness, decreased self-esteem and life satisfaction, as well as cognitive, affective, and behavioral problems that negatively impact quality of life [13, 14].

Nurses should protect individuals exposed to stigma through training to reveal their beliefs and attitudes, provide information to eliminate a lack of knowledge to prevent stigma, and change the false beliefs and information in this regard.

The objective of the research was to evaluate affiliate stigma, hopelessness, and life satisfaction in parents of children with intellectual disability.

The research sought to answer the following question:

- What is the mean score for internalized stigma, life satisfaction and hopelessness in parents who have a child with intellectual disabilities?

- Is there a relationship between the levels of internalized stigma, life satisfaction and hopelessness in parents having children with intellectual disabilities?

\section{Materials and Methods}

This descriptive study was conducted in rehabilitation and special education centers in the principal city of a province located in eastern Turkey. The sample group consisted of 203 parents who were admitted to special education and rehabilitation centers to receive training and were selected through random sampling as they met the research inclusion criteria. The adequacy of the sample size was determined by the post hoc power analysis. According to the results of this analysis, the significance level was 0.05 , and the confidence interval was $95 \%$. The effect size of the study was 0.1163 , and the power was 0.97 , indicating a sufficient sample size [15].
Research inclusion criteria: parents' children should

- have been in rehabilitation for at least 6 months;

- be 18 years of age or younger and have an intellectual disability;

- not have a very severe orthopedic disability;

- be registered in a rehabilitation center;

- live with their family.

\section{Data Collection}

The research was conducted between April 2016 and May 2017. The data were collected using the Personal Information Form, the Affiliate Stigma Scale (ASS), the Beck Hopelessness Scale (BHS), and the Satisfaction with Life Scale (SWLS).

\section{Personal Information Form}

The "Personal Information Form" was developed by the researcher in accordance with the literature and consisted of 11 items about the socio-demographic characteristics of children with disabilities and their families [13, 16, 17].

\section{Affiliate Stigma Scale}

The Turkish study of the validity and reliability of the scale developed by Mak and Cheung (2008) was carried out by Kasımoğlu and Arıkan (2020). It is a 4-point Likert-type scale consisting of 22 items (scored from 1 - "strongly agree" to 4 - "strongly disagree"). The scale items measure the cognitive, emotional, and behavioral components of affiliate stigma. The scale scores ranges from 22 to 88 , and the increasing scale scores indicate increased affiliated stigma $[9,18]$. In this study, the total Cronbach's alpha value of ASS was found to be 0.973 .

\section{Beck Hopelessness Scale}

The Turkish study of the validity and reliability of the BHS which was developed by Beck et al. (1974) in the UK was carried out by Durak (1994) [19, 20]. The scale is a personality test consisting of 20 items aimed at measuring individuals' expectations for the future. The scale scores range from 0 to 20 , and the increasing BHS total score indicates the increased levels of hopelessness. The scale consists of "Feelings About the Future", "Loss of Motivation", and "Hope" sub-scales [20]. In this study, the total Cronbach's alpha value of the BHS was 0.823, and Cronbach's alpha values of its sub-scales were as follows: 0.671 for Feelings About the Future sub-scale (FFS), 0.682 for Loss of Motivation sub-scale (LMS), and 0.691 for Hope sub-scale (HS).

\section{Satisfaction with Life Scale}

The SWLS was developed by Diener et al. [21]. The Turkish study of the validity and reliability of the SWLS was carried out by Köker [22]. The SWLS is a 5-point Likert-type scale consisting of 5 items. The total score determines the level of satisfaction with life. The total scores are classified as follows: 30-35 = "extremely satisfied", 25-29 = "very satisfied", 
20-24 = "satisfied", 15-19 = "less satisfied", 10-14 = "dissatisfied", 5-9 = "extremely dissatisfied" [22]. In this study, the total Cronbach's alpha value of the SWLS was 0.856.

\section{Data Analysis}

The data were evaluated with SPSS 17 and Lisrel 8.80 package programs. In data evaluation, the percentage, the mean score, the minimum and maximum values, the Cronbach's coefficient were used, as well as the Shapiro Wilk test was applied for normal distribution of the data and the Spearman correlation analysis was used for correlational inferences [23, 24].

\section{Results}

The mean age of parents included in the study was $40.74 \pm 7.22$ years, with $67.5 \%$ of caregiving mothers. Among them, $92.1 \%$ were married; $44.8 \%$ were primary school graduates; $59.1 \%$ lived in the city center; $74.9 \%$ had balanced income; $68 \%$ were unemployed; $77.3 \%$ had social security; $64.5 \%$ had male children with intellectual disabilities; $44.8 \%$ of the children had mild intellectual disabilities, and the average age of children was $11.40 \pm 4.62$ years.

The mean score of parents was $36.21 \pm 15.11$ in the ASS, $20.69 \pm 7.33$ in the SWLS, $5.13 \pm 5.02$ in the BHS, $0.99 \pm 1.29$ in the FFS, $2.47 \pm 1.98$ in the LMS, and $1.68 \pm 1.70$ in the HS (Table 1).

Table 1. Parents' ASS, SWLS, BHS and sub-scale mean score.

\begin{tabular}{lccc}
\hline Scales & $\mathrm{n}$ & Min-Max & $\mathrm{X} \pm$ SD \\
\hline ASS & 203 & $22-85$ & $36.21 \pm 15.11$ \\
SWLS & 203 & $5-35$ & $20.69 \pm 7.33$ \\
\hline \multicolumn{4}{l}{ BHS and sub-scales } \\
BHS & 203 & $0-18$ & \\
FFS & 203 & $0-5$ & $0.13 \pm 5.02$ \\
LMS & 203 & $0-8$ & $2.47 \pm 1.29$ \\
HS & 203 & $0-7$ & $1.68 \pm 1.70$ \\
\hline
\end{tabular}

According to Table 2, there was a statistically significant positive correlation between the ASS and the FFS, the LMS, the HS and the BHS $(p<0.05)$. As the ASS score increased, the FFS, the LMS, the HS and the BHS scores also increased. In addition, there was a statistically significant negative correlation between the ASS and the SWLS scores $(\mathrm{p}<0.05)$. The SWLS score decreased as the ASS score increased (Table 2).

There was a statistically significant negative correlation between the SWLS and the FFS, the LMS and the HS scores. The SWLS score decreased as the FFS, the LMS and the HS scores increased (Table 2). According to Table 2, there was a statistically significant negative correlation between the BHS total score and the SWLS score. The SWLS score decreased as the BHS total score increased.

\section{Discussion}

In the study, conducted to investigate affiliate stigma, hopelessness, and life satisfaction among parents of children with intellectual disabilities, parents were found to score 22 to 85 points on the ASS, and the total mean score was $36.21 \pm 15.11$. As the total ASS score ranges between 22 and 88, parents were found to have low levels of affiliated stigma. In the literature, there are very few studies investigating the level of affiliate stigma in parents of children with intellectual disabilities. According to Werner \& Shulman's study, the level of internalized stigma among parents with disabled children was low [25]. The low level of affiliate stigma is believed to be related to the spirituality of society and may be due to their beliefs that their disabled children are a God-given trust.

Parents were found to receive the mean score of $20.69 \pm 7.33$ on the SWLS, indicating that they were satisfied with their lives. In a study conducted by Kaçan Softa et al., parents of children with intellectual disabilities were found to be very satisfied with their lives [26]. In other studies, contrary to our findings, parents were found to be less satisfied with their lives [27, 30].

According to our study, parents scored 0 to 18 points on the BHS, and their mean total score was found to be $5.13 \pm 5.02$. As the total BHS score ranges between 0 and 20, parents were found to have low levels of hopelessness. There have been studies in which the hopelessness level in parents of children with intellectual disabilities was high [31] and moderate [32]. In some studies, similar to our findings, the hopelessness level of parents with children with mental disabilities was observed to be low [33,34]. The low level of hopelessness may be due to parental spirituality along with the increased legal rights the state provides for individuals with disabilities and their families, and the institutions and organizations that provide services in this regard.

In our study, parents were found to score $0-5$ points on the FFS of the BHS, with the total mean score of $0.99 \pm 1.29$. As the minimum and maximum scores are 0 and 5, respectively, parents were found to receive a low score on the FFS, meaning that their expectations for the future were high.

Parents were found to score $0-8$ points on the LMS of the BHS, with the total mean score of $2.47 \pm 1.98$. As the subscale scores range from 0 to 8 , the loss of motivation levels among parents were found to be low.

According to our study, parents were found to score 0-7 points on the HS of the BHS, with the total mean score of $1.68 \pm 1.70$. The study with parents having children with intellectual disabilities conducted by Eş revealed that the levels of the FFS, which is one of the hopelessness sub-scale, were high and the levels of the LMS and the HS were low [35]. Contrary to our findings, the study carried out by Cabar revealed high levels of the FFS, the LMS and the HS [32].

The levels of affiliate stigma in parents increased, the levels of life satisfaction decreased, and the levels of hopelessness increased. The presence of a child with a disability causes many difficulties and drastic changes in the family $[13,36,39]$. 
Table 2. Relationship between parents' ASS, SWLS, BHS and sub-scales ( $\mathrm{n}=203)$.

\begin{tabular}{llccccc}
\hline \multirow{2}{*}{ Scales } & & \multicolumn{4}{c}{ BHS and Sub-Scales } & \multirow{2}{*}{ SWLS } \\
\cline { 3 - 6 } & & FFS & LMS & HS & BHS & \\
\hline \multirow{2}{*}{ ASS } & $\mathrm{r}$ & $0.390^{* *}$ & $0.182^{* *}$ & $0.297^{* *}$ & $0.321^{* *}$ & $-0.306^{* *}$ \\
& $\mathrm{p}$ & 0.000 & 0.009 & 0.000 & 0.000 & 0.000 \\
\hline \multirow{2}{*}{ SWLS } & $\mathrm{r}$ & $-0.349^{* *}$ & $-0.311^{* *}$ & $-0.396^{* *}$ & $-0.434^{* *}$ & - \\
& $\mathrm{p}$ & 0.000 & 0.000 & 0.000 & 0.000 & - \\
\hline
\end{tabular}

Contrary to these findings, Beighton \& Wills found that having a child with a disability brings about many positive changes. Parents expressed that having a child with a disability empowered them, increased their self-confidence, gave more meaning in their lives, increased their spirituality, and that they had positive experiences as a result of the disability of their child and these attitudes led to a change in negative thoughts in society [40]. Parents also stated that they have successfully adapted to the stress of raising children, in line with all these experiences. In the study conducted by Akçamak, mothers expressed that being a mother of children with intellectual disabilities is not only difficult, but also a happy feeling [41]. These positive feelings and spirituality of parents of children with disabilities are believed to be able to decrease hopelessness and increase life satisfaction, to decrease discriminatory attitudes and behaviors of the society. In line with these results, life satisfaction of parents is believed to lead to a reduction in their future anxiety and a more hopeful view of life.

Hope is one of the most important factors affecting life satisfaction positively $[42,43]$. In this study, there was a weak negative correlation between the BHS total score and the SWLS score. Life satisfaction refers to a person's overall positive evaluation of their life and satisfaction with their whole life. In the literature, positive emotions have been reported to increase life satisfaction [12]. Parental lack of expectations from life due to their children's disability is thought to cause them to not enjoy their lives, and consequently their life satisfaction may decrease.

The FFS, LMS, and HS scores increased as the ASS score increased as well. Exposure to negative community attitudes may lead to an increase in better life expectations in the future, loss of motivation due to the influence of negative judgments, and an increase in the parents' hope for a better life for their child with a disability and themselves.

The SWLS score was found to decrease as the FFS score increased. Having exaggerated and unrealistic expectations, instead of embracing the current situation and opportunities, especially about their children and their future, is believed to decrease parental life satisfaction.

Motivation is defined as the activation of the inner state that causes individuals to behave in a certain direction, pushes them to act in order to realize the behavior and induces individuals to do something [44]. In our study, the SWLS score decreased as the LMS score increased. The increased loss of motivation in parents is believed to make it difficult for parents to act against the negative impact of having a child with a disability and cope with stress, negatively affecting their efforts to find solutions to problems, and increased stress may decrease parental life satisfaction.

Hope can be defined as the desire for something to happen [45]. In our study, the SWLS score was found to decrease as the HS score increased. Several studies revealed that hope increased life satisfaction [42, 43]. Parental increasing unrealistic expectations for their children with intellectual disabilities and realizing the fact that these expectations cannot be met by their children may lead to a decrease in their life satisfaction.

\section{Conclusions}

In case of increasing parental affiliate stigma, their hopelessness increased, and life satisfaction decreased. In line with these results, it may be suggested to plan awareness training and repeat these trainings at regular intervals to increase social acceptance and attitudes towards people with disabilities, as well as hope and life satisfaction of parents having children with intellectual disabilities.

\section{Prospects of Further Researches}

There are very few studies on the levels of affiliate stigma in parents having children with intellectual disabilities, and this paper is one of the first studies in this area in our country. This study emphasized that parents of children with intellectual disabilities are exposed to negative attitudes by society that negatively affect parental life satisfaction and hope. Therefore, it drew attention to the necessity of psychological support for nurses, considering the family in a holistic way. It can theoretically contribute to understanding the difficulties experienced by parents having children with intellectual disabilities, addressing and solving the problems of these parents.

\section{Ethical Statement}

Before starting the research, the approval of the Ethics Committee and the written permission of the Provincial Directorate of National Education were obtained for the studied rehabilitation centers. The parents, who met the research inclusion criteria and agreed to participate in the research, were informed about the research in accordance with the "Principle of Informed Consent" and told that they were free to participate in the study according to the "Principle of Respect 
for Autonomy", and they were ensured that their information would be kept confidential in accordance with the "Privacy and Confidentiality Protection" policy. Written consent was obtained before participating in the study.

\section{Informed Consent}

Informed consent was obtained from all the parents before the study.

\section{Conflict of Interest}

The authors stated no conflict of interest.

\section{Financial Disclosure}

The authors received no financial support for the research, authorship, and/or publication of this article.

\section{Acknowledgements}

We, authors, acknowledge the contributions of all parents who took part in the study and thank them for their participation in the research.

\section{References}

[1] Kaytez N, Durualp E, Kadan G. Evaluation of requirements and stress levels of the families having disabled child. J Res Educ Teach. 2015;19.

[2] Akça F, Özyürek A.The distress toleration status, depression, anxiety and stress levels of parents who have normally developed children and who have intellectual disability children. Journal of History Culture and Art Research [Internet]. 2019;8(1):347. Available from: https://doi.org/10.7596/taksad.v8i1.1787

[3] Shree A, Shukla PC. Intellectual disability: definition, classification, causes and characteristics. Learning Community-An International Journal of Educational and Social Development [Internet]. 2016;7(1):9. Available from: https://doi.org/10.5958/2231-458X.2016.00002.6

[4] Eldeniz Çetin M, Sönmez M. Identification of the problems experienced by mothers with children with multiple disabilities. Elem Educ Online [Internet]. 2018;17(3):1252-1267. Available from: https://doi.org/10.17051/ilkonline.2018.466339

[5] Badu E. Experiences of parents of children with intellectual disabilities in the Ashanti Region of Ghana. Journal of Social Inclusion [Internet]. 2016;7(1):20. Available from: https://doi.org/10.36251/josi.100

[6] K1ş A, Yüksel H. Social problems and coping mechanisms in families of children with special needs. Ankara
Üniversitesi Eğitim Bilimleri Fakültesi Özel Eğitim Dergisi [Internet]. 2019;20(3):535-559. Available from: https://doi.org/10.21565/ozelegitimdergisi.493089

[7] Turan Gurhopur FD. Family burden among parents of children with intellectual disability. Journal of Psychiatric Nursing [Internet]. 2017;8(1):9-16. Available from: https://doi.org/10.14744/phd.2017.87609

[8] Masulani-Mwale C, Kauye F, Gladstone M, Mathanga D. Prevalence of psychological distress among parents of children with intellectual disabilities in Malawi. BMC Psychiatry [Internet]. 2018;18(1). Available from: https://doi.org/10.1186/s12888-018-1731-X

[9] Mak WWS, Cheung RYM. Affiliate stigma among caregivers of people with intellectual disability or mental illness. Journal of Applied Research in Intellectual Disabilities [Internet]. 2008;21(6):532-545. Available from: https://doi.org/10.1111/j.1468-3148.2008.00426.x

[10] Özmen S, Erdem R. Conceptual framework of the stigmatization. Suleyman Demirel Univ J Fac Econ Adm Sci. 2018;23(1).

[11] Luca M, Grazia Chisari C, D’Amico E, Patti F. Hopelessness in multiple sclerosis: psychological and organic correlates. Journal of Psychiatry and Psychiatric Disorders [Internet]. 2019;03(06):241-244. Available from: https://doi.org/10.26502/jppd.2572-519X0078

[12] Öztop H, Kinaci B. An analysis of the factors that affect the life satisfaction of elderly turks living in Australia. Journal of Administrative Sciences and Policy Studies [Internet]. 2016;4(1):21-35. Available from: https://doi.org/10.15640/jasps.v4n1a2

[13] Cangür Ş, Civan G, Çoban S, Koç M, Karakoç H, Budak S, et al. Comparative assessment of social life participation of families which have physically and/or mentally handicapped individual. Düzce Univ J Heal Sci Inst. 2013;3(3):1-9. Available from: https://docplayer.biz.tr/19491349

[14] Papadopoulos C, Lodder A, Constantinou G, Randhawa G. Systematic review of the relationship between autism stigma and informal caregiver mental health. Journal of Autism and Developmental Disorders [Internet]. 2018;49(4):1665-1685. Available from: https://doi.org/10.1007/s10803-018-3835-z

[15] Bursal M. Basic data analysis with SPSS. Second Ed. Ankara: Ani Publishing; c2019.

[16] Marrus N, Hall L. IIntellectual disability and language disorder. Child and Adolescent Psychiatric Clinics of North America [Internet]. 2017;26(3):539-554. Available from: https://doi.org/10.1016/j.chc.2017.03.001 
[17] Patel DR, Apple R, Kanungo S, Akkal A. Intellectual disability: definitions, evaluation and principles of treatment. Pediatric Medicine [Internet]. 2018;1:11. Available from: https://doi.org/10.21037/pm.2018.12.02

[18] Kasimoglu N, Arikan D. Validity and reliability of the Turkish version of the affiliate stigma scale in parents of children with intellectual disability. International Journal of Caring Sciences. 2020;13(1):665-674. Available from: http://www.internationaljournalofcaringsciences.org

[19] Beck AT, Weissman A, Lester D, Trexler L. The measurement of pessimism: the hopelessness scale. Journal of Consulting and Clinical Psychology [Internet]. 1974;42(6):861-865. Available from: https://doi.org/10.1037/h0037562

[20] Durak A. Validity and reliability of Beck hopelessness scale. Turkish J Psychol. 1994;9(11):1-11.

[21] Diener E, Emmons RA, Larsen RJ, Griffin S. The satisfaction with life scale. Journal of Personality Assessment [Internet]. 1985;49(1):71-75. Available from: https://doi.org/10.1207/s15327752jpa4901_13

[22] Köker S. Comparison of life satisfaction among normal and problematic adolescents. Ankara: University Institute of Social Sciences; 1991.

[23] Büyüköztürk Ş. Data analysis book for social sciences. 26th ed. Ankara: Pegem Academy Publishing; c2019.

[24] Büyüköztürk Ş, Şekercioğlu G, Çokluk Ö. Multivariate statistics for social sciences: SPSS and LISREL applications. Fifth Edit. Ankara: Pegem Academy Publishing; c2018.

[25] Werner S, Shulman C. Does type of disability make a difference in affiliate stigma among family caregivers of individuals with autism, intellectual disability or physical disability? Journal of Intellectual Disability Research [Internet]. 2014;59(3):272-283. Available from: https://doi.org/10.1111/jir.12136

[26] Kaçan Softa H, Öztürk A, Sonkaya C. Analysis of family burden and life satisfaction of parents having children with mental disabilities. International Journal of Psychiatry and Psychological Researches [Internet]. 2016;(5):37. Available from: https://doi.org/10.17360/UHPPD.2016516565

[27] İnce ZE, Tüfekci FG. Evaluation of marital adjustment and life satisfaction in parents with children with disabilities and determination of the affecting factors. Gümüşhane Univ J Heal Sci. 2015;4(1):102-112.

[28] Shukla S. A study of life satisfaction of parents of mentally challenged and normal children. International Journal of Research in all Subjects in Multi Languages. 2017;5(12):1-4.
[29] Gebeyehu F, Sahile A, Ayalew M. Burden, social support, and life satisfaction among caregivers of children with intellectual disability: the case of Felege Abay and Shembt primary schools, Bahir Dar, Ethiopia. International Quarterly of Community Health Education [Internet]. 2019;39(3):147-153. Available from: https://doi.org/10.1177/0272684X18819974

[30] Aktan O, Orakcı Ş, Durnalı M. Investigation of the relationship between burnout, life satisfaction and quality of life in parents of children with disabilities. European Journal of Special Needs Education [Internet]. 2020;35(5):679-695. Available from: https://doi.org/10.1080/08856257.2020.1748429

[31] Hemati Alamdarloo G, Majidi F. Feelings of hopelessness in mothers of children with neurodevelopmental disorders. International Journal of Developmental Disabilities [Internet]. 2020;1-10. Available from: https://doi.org/10.1080/20473869.2020.1736886

[32] Cabar DH, Altay B, Saraçoğlu E. Determination of the hopelessness level of parents with disabled children. J Acad Soc Sci. 2019;7(97):53-67. Available from: https://doi.org/10.29228/ASOS.36774

[33] Konukbay D, Arslan F. The analysis of hopelessness levels and problem solving skills of parents with the disabled children. Int J Caring Sci. 2015;8(2):344-355.

[34] Awan EA, Bibi F, Chaudhry AG. Relationship of depression, hopelessnes and associated attitude among parents of mentally retarded children. Pakistan Assoc Anthropol Islam Pakista. 2015;27(1):723-726.

[35] Eş A. Relationship between the acceptation and the hopelessness of the mothers of children with menthal disability. İstanbul: Yeditepe University Institute of Social Sciences; 2013.

[36] Şimşek D. The relationship between the percepted level of social support and level of hopelesness in mother of autistc children. Istanbul: Beykent University Institute of Social Sciences; 2015.

[37] Cigerli O, Topsever P, Alvur T, Gorpelioglu S. Parental experiences since the diagnosis of disability in families with a disabled child: accepting the difference. Turkish Journal of Family Medicine \& Primary Care [Internet]. 2014;8(3):75. Available from: https://doi.org/10.5455/tjfmpc.159761

[38] The Institute for Social Development Studies. Economic costs of living with disabilities and stigma in VietNam. Ha Noi: Workers' Publishing House; c2013. Available from: https://www.aspeninstitute.org/ 
[39] Balc1 S. Determining the difficulties faced by families with intellectual disability children and the burden on the family. Journal of Psychiatric Nursing [Internet]. 2019;10(2):124-130. Available from: https://doi.org/10.14744/phd.2018.05657

[40] Beighton C, Wills J. Are parents identifying positive aspects to parenting their child with an intellectual disability or are they just coping? A qualitative exploration. Journal of Intellectual Disabilities [Internet]. 2017;21(4):325-345. Available from: https://doi.org/10.1177/1744629516656073

[41] Akçamak GP. Life experiences of mothers of children with intellectual disability. Istanbul: Boğaziçi University Institute of Social Sciences; 2014.

[42] Hassan K, Sadaf S, Saeed A, Idrees A. Relationship between hope, optimism and life satisfaction among adolescents. International Journal of Scientific \& Engineering Research [Internet]. 2018;9(10):1452-1457. Available from: https://doi.org/10.14299/ijser.2018.10.09
[43] Raats C, Adams S, Savahl S, Isaacs S, Tiliouine H. The relationship between hope and life satisfaction among children in low and middle socio-economic status communities in Cape Town, South Africa. Child Indicators Research [Internet]. 2018;12(2):733-746. Available from: https://doi.org/10.1007/s12187-018-9549-0

[44] Doğan S, Aslan M. A theoretical view of extrinsic motivation, intrinsic motivation and performance interaction. Süleyman Demirel University Visionary Journal [Internet]. 2020;11(26):291-301. Available from: https://doi.org/10.21076/vizyoner.638479

[45] Ağır M. Quality of life, values and hope-hopelessness. J Marmara Soc Res. 2017;11:85-103.

Received: 2021-01-12

Revised: 2021-02-14

Accepted: 2021-03-03 